\title{
The local and global imperative to raise public awareness and knowledge about dementia
} O dever local e global de melhorar a conscientização e o conhecimento sobre demência Brian Lawlor ${ }^{1}$

${ }^{1}$ Conolly Norman Professor of Old Age Psychiatry, Co-Director, Global Brain Health Institute, Trinity College Dublin, Ireland.

Correspondence:

Brian Lawlor; Clinical Director, NEIL Research Programme, Room 345 Lloyd Building, Trinity College Institute of Neuroscience, Dublin 2; E-mail:brian.lawlor@gbhi.org

Conflict of interest:

There is no conflict of interest to declare.

Received 02 October 2018; Accepted 09 October 2018.

\section{(c) BY}

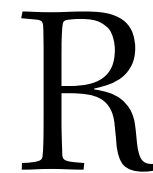

aising public awareness and advocacy about an issue or condition is key to developing and implementing effective strategies to address it. If the general public have a poor understanding of a particular condition or believe that nothing can be done, then they will not raise their collective voice to ensure that action is taken by policy makers and governments. Increased public awareness and advocacy around HIV and cancer has led to a transformation of services and treatments worldwide and stimulated research and innovation that has produced very tangible results in terms of disease modifying interventions and cures.

By contrast, dementia, despite its global significance in terms of human impact and health and social care costs, has been lurking in the backwaters of public awareness, cloaked in stigma, and is only now beginning to come out of the shadows. The current narrative for dementia is a pessimistic one, whereby dementia is one of the most feared conditions in people over the age of 50. The World Health Organization (WHO) Global Action Plan on Dementia encourages all member countries to implement campaigns to raise public and professional awareness about dementia and to promote the creation of dementia inclusive societies ${ }^{1}$. Greater optimism, hope and knowledge around dementia can bring about earlier assessment and diagnosis, creates more support and community engagement around dementia and importantly spreads the hopeful message that something can be done, particularly around addressing modifiable risk factors and the potential for dementia prevention. The evidence from public awareness surveys, primarily from high income countries, indicates that there are significant gaps in knowledge about dementia still exist and that dementia continues to be seen by many as an inevitable and a natural part of the ageing process ${ }^{2}$. In a high income country, such as Ireland, the general public is less knowledgeable about dementia than cancer and only about half the population are aware that addressing modifiable risk factors such as hypertension, obesity and low exercise levels has the potential to reduce the risk of developing dementia 3 .

Increased awareness and advocacy and the implementation of national dementia strategies in high income countries is helping to change the narrative and understanding of what dementia is. In particular, the use of personal stories shows the lived experience of dementia and illustrates how many people can live well with dementia with the appropriate supports and care. However, the situation for low- and middle-income countries that face the greatest rise in dementia cases during the next 30-50 years is less encouraging. Here, the level of knowledge and awareness amongst the general public is largely unknown due to the lack of survey information in these settings ${ }^{4}$. For this reason, that Amado and Brucki's paper in this issue of Arquivos de Neuro-Psiquiatria ${ }^{5}$ is timely and important. This study reports on the results of an online survey on knowledge of Alzheimer's disease by patients and their relatives of a tertiary memory clinic, as well as by anyone older than 18 years who had access to the clinic's social media pages. The survey which was completed by around 1400 people showed an overall poor level of knowledge about Alzheimer's disease even in people who had relatives affected by dementia. Education level as expected was associated with better knowledge. This was a non-representative sample and therefore likely biased, targeting those with better education and those who already had some knowledge of dementia. For these reasons, the true level of awareness and knowledge about Alzheimer's disease in Brazil is likely to be far lower. 
Public awareness campaigns are a key component of all national dementia strategies and are necessary to drive improvements in care, research and innovation around dementia. Brazil has approximately 1.6 million people with dementia $^{6,7}$ and it has been estimated that only 1 in 4 cases are diagnosed ${ }^{8}$. The results of Amado and Brucki's study ${ }^{5}$ highlight the imperative to raise public awareness and knowledge around this condition as part of any Brazilian national dementia plan. It would be important to carry out representative surveys before and after delivering public awareness campaigns to evaluate the effectiveness and impact of such campaigns and to continue to measure awareness and knowledge going forward. Studies of the level of awareness from different countries would be important as we try to improve public and professional awareness about dementia and create dementia inclusive societies worldwide. Comparative tables by country could provide an index of progress in changing knowledge and attitudes to dementia and act as a stimulus to encourage governments and countries like Brazil to invest in delivering the best care and support for people with dementia through the implementation of a national dementia strategy.

\section{References}

1. Dua T, Seeher KM, Sivananthan S, Chowdhary N, Pot AM et al. World Health Organization's Global Action Plan on the Public Health response to dementia 2017-2025. Alzheimer's \& Dementia 2017;13(7 suppl):P1450-1. https://doi.org/10.1016/j.jalz.2017.07.758

2. Cahill S, Pierce M, Werner P, Darley A, Bobersky A. A systematic review of the public's knowledge and understanding of Alzheimer's disease and dementia. Alzheimer Dis Assoc Disord.. 2015 JulSep;29(3):255-75. https://doi.org/10.1097/WAD.0000000000000102

3. Glynn RW, Shelley E, Lawlor BA. Public knowledge and understanding of dementia-evidence from a national survey in Ireland. Age Ageing. 2017 Sep;46(5):865-9. https://doi.org/10.1093/ageing/afx082

4. Cations M, Radisic G, Crotty M, Laver KE. What does the general public understand about prevention and treatment of dementia? A systematic review of population-based surveys. PLoS One. $2018 \mathrm{Apr}$ 19;13(4):e0196085. https://doi.org/10.1371/journal.pone.0196085
5. Amado DK, Brucki SM. Brazilians' knowledge about Alzheimer's disease. Arq Neuropsiquiatr. 2018;76(11):776-83. https://doi.org/10.1590/0004-282X20180106

6. Herrera Junior E, Caramelli P, Silveira AS, Nitrini R. Epidemiologic survey of dementia in a community-dwelling Brazilian population. Alzheimer Dis Assoc Disord. 2002 Apr-Jun;16(2):103-8. https://doi.org/10.1097/00002093-200204000-00007

7. Scazufca M, Menezes PR, Vallada HP, Crepaldi AL, Pastor-Valero M, Coutinho LM, et al. High prevalence of dementia among older adults from poor socioeconomic backgrounds in São Paulo, Brazil. Int Psychogeriatr. 2008 Apr;20(2):394-405. https://doi.org/10.1017/S1041610207005625

8. Nakamura AE, Opaleye D, Tani G, Ferri CP. Dementia underdiagnosis in Brazil. Lancet. 2015 Jan;385(9966):418-9. https://doi.org/10.1016/S0140-6736(15)60153-2 